\title{
PLANIRANJE PROIZVODNJE ELEMENATA KONSTRUKCIJE MONTAŽNE HALE ANALIZOM RESURSA
}

\section{PLANNING OF THE PRODUCTION OF STRUCTURAL ELEMENTS OF THE PREFABRICATED HALL BY RESOURCE ANALYSIS}

\author{
Jelena Planinac Jokić, Jasmina Dražić, Fakultet tehničkih nauka, Novi Sad
}

\section{Oblast - GRAĐEVINARSTVO}

Kratak sadržaj - U radu su analizirani problemi vezani za proizvodnju elemenata konstrukcije montažne hale. Planiranje proizvodnje rađeno je u tri varijante s ciljem da se analizom osnovnih resursa i dinamike proizvodnje predloži najpovoljnije rešenje.

Ključne reči: montažna hala, elementi, proizvodnja (prefabrikacija), planiranje, resursi

Abstract - This thesis analyses the problems related to the production of elements of the construction of the prefabricated hall. Production planning is done in three variants with the aim of proposing the most favorable solution by analyzing the basic resources and the dynamics of production.

Keywords: prefabricated hall, elements, production (prefabrication), planning, resources

\section{UVOD}

Montažni način građenja podrazumeva skup tehničkih, tehnoloških i organizacionih mera i metoda, koje se primenjuju sa ciljem da se proizvodnja ubrza i olakša i da se izvrši racionalizacija utroška resursa za tu proizvodnju [1].

U ovom radu je detaljno planirana proizvodnja elemenata konstrukcije montažne hale: temeljnih čašica, temeljnih greda, stubova, nosača kranske staze, glavnih nosača, rožnjača i olučnih greda. Planirana je proizvodnja elemenata na osnovu analize osnovnih resursi, količina materijala (betona, oplate i armature) i radne snage. Planiranje proizvodnje rađeno je u tri varijante:

- Varijanta I - bez vremenskih i prostornih ograničenja

- Varijanta II - sa vremenskim ograničenjem i

- Varijanta III - sa prostornim ograničenjem (ograničen broj kalupa).

Pri razmatranju varijanti planiranja proizvodnje elemenata, uveden je princip paralelizacije u radu, pa je proizvodnja organizovana sa jednom i dve radne brigade. Cilj rada je bio da se za sve elemente konstrukcije montažne hale, na osnovu analize osnovnih resursa $\mathrm{i}$ dinamike proizvodnje, predloži najpovoljnija (optimalna) varijanta.

\section{NAPOMENA:}

Ovaj rad proistekao je iz master rada čiji mentor je bila dr Jasmina Dražić, red.prof.

\section{SPECIFIKACIJA ELEMENATA KONSTRUKCIJE HALE}

Razmatrani objekat je skladište sa upravnom zgradom $\mathrm{u}$ Rumenki, čiji je investitor PEZOS EXPORT-IMPORT doo, iz Petrovaradina. Podeljen je u dve celine:

- skladište - pravougaone osnove dimenzija osovinski $20,82 \mathrm{~m}$ x 105,02m, unutrašnje čiste visine $8,65 \mathrm{~m}$ (od gotovog poda do donje ivice glavnog nosača) $i$

- upravna zgrada koja je funkcionalno povezana sa samim skladištem.

U radu su analize rađene za elemente konstrukcije tipajednobrodna hala. Konstrukcija objekta je montažna armiranobetonska iz programa "NOVOTEHNA" Novi Sad. Tabela 1. Geometrijske karakteristike temeljnih čašica

\begin{tabular}{|c|c|c|c|}
\hline \multicolumn{4}{|c|}{ TEMELJNE ČAŠICE } \\
\hline 4. & & \multicolumn{2}{|c|}{$\begin{array}{c}\text { Temelji samci se izvode na } \\
\text { licu mesta u betonu, MB-30 i } \\
\text { armaturom RA 400/500 i GA } \\
\text { 240/360, na dubini fundiranja } \\
\text { Df=1,85m. } \\
\text { Postoje dva tipa temeljnih } \\
\text { čašica: TČ1 i TČ } 2 \text {. Čašice su } \\
\text { kvadratnog poprečnog preseka, } \\
\text { visine } 110 \mathrm{~cm} \text { sa debljinom } \\
\text { zida od } 20-25 \mathrm{~cm} \text {. }\end{array}$} \\
\hline šifra & $\begin{array}{c}\text { geometrijske } \\
\text { karakteristike } \\
\text { b/d/h }[\mathrm{cm}]\end{array}$ & kom. & $\begin{array}{c}\text { zapremina } \\
{\left[\mathrm{m}^{3}\right]}\end{array}$ \\
\hline TČ1 & $110 / 110 / 110$ & 24 & 0.874 \\
\hline TČ2 & $110 / 100 / 110$ & 20 & 0.824 \\
\hline
\end{tabular}

Tabela 2. Geometrijske karakteristike temeljnih greda

\begin{tabular}{|c|c|c|c|}
\hline \multicolumn{4}{|c|}{ TEMELJNE GREDE } \\
\hline šfra & $\begin{array}{c}\text { geometrijske } \\
\text { karakteristike } \\
\text { b/d/h [cm] }\end{array}$ & kom. & $\begin{array}{c}\text { Temeljne grede se } \\
\text { prozvode u armiranom } \\
\text { betonu, MB-40, } \\
\text { armaturom RA400/500. }\end{array}$ \\
\hline TG1 & $20 / 105 / 470$ & 31 & 0.930 \\
\hline TG1a & $20 / 105 / 470$ & 1 & 0.875 \\
\hline TG2 & $20 / 105 / 335$ & 4 & 0.650 \\
\hline TG2a & $20 / 105 / 350$ & 2 & 0.680 \\
\hline TG3 & $20 / 105 / 980$ & 2 & 1.630 \\
\hline TG4 & $20 / 105 / 950$ & 1 & 1.940 \\
\hline TG4a & $20 / 105 / 950$ & 1 & 1.570 \\
\hline TG4b & $20 / 105 / 950$ & 1 & 1.620 \\
\hline
\end{tabular}


Glavna konstrukcija je prefabrikovana armirano-betonska, koju čine montažni elementi: temeljne čašice, temeljne grede, stubovi, nosači kranske staze, glavni krovni nosači, rožnjače i olučne grede [2].

Specifikacija elemenata konstrukcije prikazana je u tabelama 1, 2, 3, 4, 5, 6 i 7 .

Tabela 3. Geometrijske karakteristike stubova

\begin{tabular}{|c|c|c|c|}
\hline \multicolumn{4}{|c|}{ STUBOVI } \\
\hline 8 & 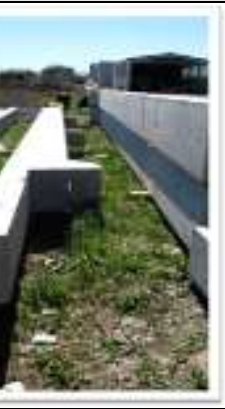 & \multicolumn{2}{|c|}{$\begin{array}{c}\text { Stubovi se izvode od } \\
\text { betona kvaliteta } \\
\text { MB-40 i MB-30, } \\
\text { dimenzionisani su prema } \\
\text { statičkom proračunu i } \\
\text { armirani rebrastom } \\
\text { armaturom RA400/500 i } \\
\text { GA240/360, sa } \\
\text { adekvatnim rešenjima } \\
\text { detalja. }\end{array}$} \\
\hline šifra & $\begin{array}{c}\text { geometrijske } \\
\text { karakteristike } \\
\text { b/d/h }[\mathrm{cm}]\end{array}$ & kom. & $\begin{array}{c}\text { zapremina } \\
{\left[\mathrm{m}^{3}\right]}\end{array}$ \\
\hline S1 & $50 / 50 / 1050$ & 12 & 2.760 \\
\hline S1a & $50 / 50 / 1050$ & 2 & 2.760 \\
\hline S1b & $50 / 50 / 1117$ & 1 & 2.810 \\
\hline S1b-I & $50 / 50 / 1117$ & 1 & 2.810 \\
\hline S1c & $50 / 50 / 1117$ & 1 & 2.810 \\
\hline S1d & $50 / 50 / 1117$ & 1 & 2.810 \\
\hline S1e & $50 / 50 / 1050$ & 2 & 2.760 \\
\hline S1f & $50 / 50 / 1050$ & 2 & 2.760 \\
\hline $\mathrm{S} 2$ & $50 / 50 / 1223$ & 1 & 2.970 \\
\hline S2-I & $50 / 50 / 1223$ & 1 & 2.970 \\
\hline S3 & $40 / 50 / 1115$ & 19 & 2.190 \\
\hline S3a & $40 / 50 / 1115$ & 1 & 2.190 \\
\hline
\end{tabular}

Tabela 4. Geometrijske karakteristike nosača kranske staze

\begin{tabular}{|c|c|c|c|}
\hline \multicolumn{4}{|c|}{ NOSAČI KRANSKE STAZE } \\
\hline $\int_{1}^{2}$ & 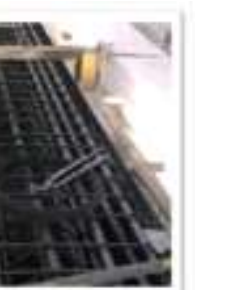 & \multicolumn{2}{|c|}{$\begin{array}{l}\text { Nosači kranske staze } \\
\text { proizvode se od } \\
\text { betona MB-40, sa } \\
\text { ugrađenom } \\
\text { armaturom } \\
\text { RA400/500 i GA } \\
240 / 360 .\end{array}$} \\
\hline šifra & $\begin{array}{c}\text { geometrijske } \\
\text { karakteristike } \\
\text { b/d/h }[\mathrm{cm}]\end{array}$ & kom. & $\begin{array}{c}\text { zapremina } \\
{\left[\mathrm{m}^{3}\right]}\end{array}$ \\
\hline NKS1 & $40 / 110 / 1028$ & 16 & 4.420 \\
\hline NKS1 a & $40 / 110 / 1054$ & 2 & 4.480 \\
\hline NKS2 & $40 / 110 / 1174$ & 2 & 5.000 \\
\hline
\end{tabular}

Tabela 5. Geometrijske karakteristike glavnih nosača

\begin{tabular}{|c|c|c|c|}
\hline \multicolumn{3}{|c|}{ GLAVNI NOSAČI } \\
\hline & $\begin{array}{c}\text { Glavni nosači se izrađuju od } \\
\text { betona kvaliteta MB-50 i armature } \\
\text { tipa RA400/500. Krovnu } \\
\text { konstrukciju objekta hale čine: } \\
\text { glavni krovni ,dvopojasni“ nosač } \\
\text { tipa GN1, raspona L=20,50m i } \\
\text { nosač GN2, tipa „T“110. }\end{array}$ \\
\hline šifra & $\begin{array}{c}\text { geometrijske } \\
\text { karakteristike } \\
\text { b/d/h [cm] }\end{array}$ & kom. & $\begin{array}{c}\text { zapremina } \\
\text { [m³ }\end{array}$ \\
\hline GN1 & $40 / 254 / 2050$ & 9 & 5.460 \\
\hline GN2 & $35 / 110 / 1034$ & 4 & 2.130 \\
\hline
\end{tabular}

Tabela 6. Geometrijske karakteristike rožnjača

\begin{tabular}{|c|c|c|c|}
\hline \multicolumn{3}{|c|}{ ROŽNJAČE } & \multicolumn{2}{c|}{$\begin{array}{c}\text { Rožnjače se } \\
\text { proizvode od betona } \\
\text { MB-40 i armirane } \\
\text { su sa rebrastom } \\
\text { armaturom } \\
\text { RA400/500, a za } \\
\text { uzengije se koristi } \\
\text { armatura }\end{array}$} \\
\hline šifra & $\begin{array}{c}\text { geometrijske } \\
\text { karakteristike } \\
\text { b/d/h [cm] }\end{array}$ & \multicolumn{2}{|c|}{$\begin{array}{c}\text { GA240/360. } \\
\text { kom. }\end{array}$} \\
\hline R1 & $20 / 68 / 1028$ & 36 & 1.13 \\
\hline R1a & $20 / 66.5 / 1028$ & 9 & 1.13 \\
\hline R2 & $20 / 68 / 1148$ & 4 & 1.27 \\
\hline R2a & $20 / 66.5 / 1148$ & 1 & 1.27 \\
\hline
\end{tabular}

Tabela 7. Geometrijske karakteristike olučnih greda

\begin{tabular}{|c|c|c|c|}
\hline \multicolumn{3}{|c|}{ OLUČNE GREDE } \\
\hline & $\begin{array}{c}\text { Olučne grede su } \\
\text { elementi "T" preseka } \\
\text { visine } \mathrm{h}=60 \mathrm{~cm} \text {, širine } \\
\text { flanše } \mathrm{b}=50 \mathrm{~cm} \text { i širine } \\
\text { rebra br=15cm, } \\
\text { Proizvodi se dva tipa, } \\
\text { OG1 i OG2. }\end{array}$ \\
\hline šifra & $\begin{array}{c}\text { geometrijske } \\
\text { karakteristike } \\
\text { b/d/h [cm] }\end{array}$ & kom. & $\begin{array}{c}\text { zapremina } \\
{\left[\mathrm{m}^{3}\right]}\end{array}$ \\
\hline OG1 & $50 / 60 / 1028$ & 18 & 1.660 \\
\hline OG2 & $50 / 60 / 1148$ & 2 & 1.850 \\
\hline
\end{tabular}

\section{OSNOVNI MATERIJAL ZA PROIZVODNJU ELEMENATA I VREME UGRAĐIVANJA}

Resursi na osnovu kojih su rađene analize u ovom radu obuhvatile su osnovni materijal za proizvodnju elemenata, armaturu, oplatu (kalupe) i beton. Na osnovu internih normi preduzeća NOVOTEHNA (mereni su utrošci osnovnih materijala, kao i vreme potrebno za njihovo ugrađivanje) [2], a prema specifikaciji elemenata konstrukcije, izračunate su ukupne količine materijala za sve elemente konstrukcije i vreme potrebno za njihovo ugrađivanje. Izlazni rezultati su prikazani grafikonima na slikama 1, 2, 3, 4, 5 i 6. 


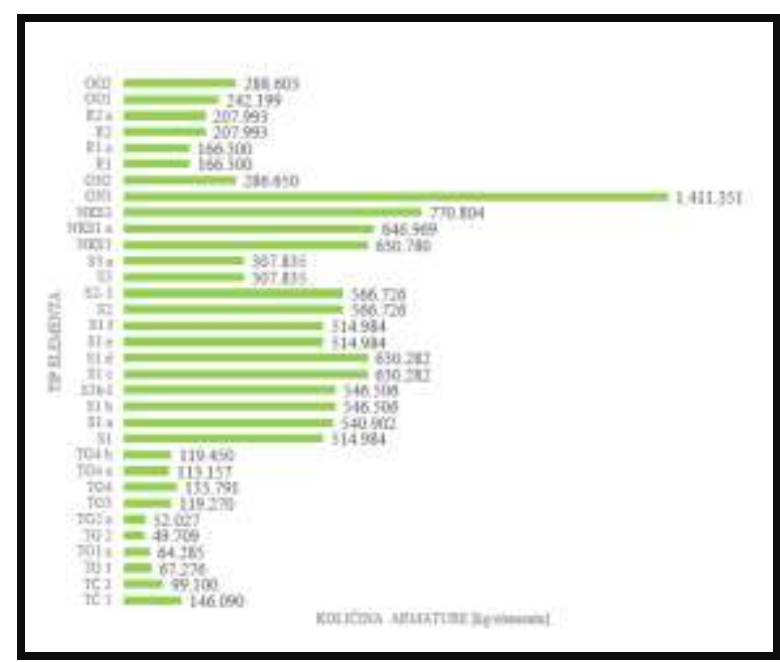

Slika 1. Ukupan utrošak armature po tipu elementa

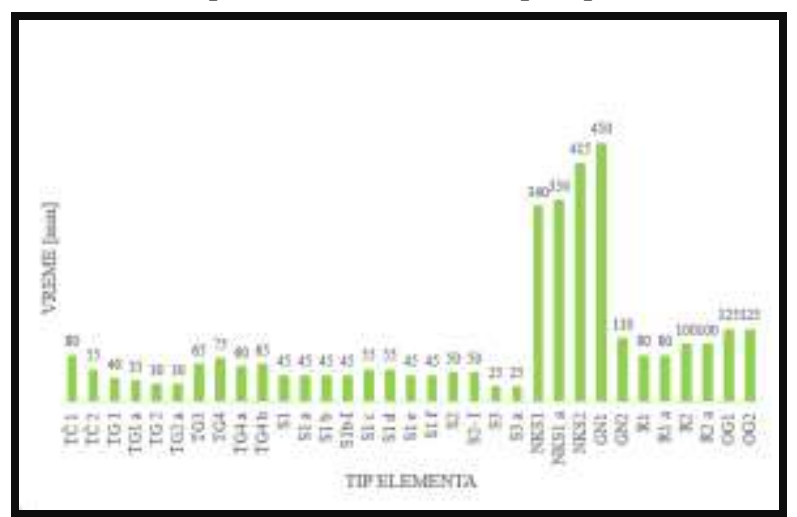

Slika 2. Prosečno vreme za ugrađivanje armature po tipovima elementa

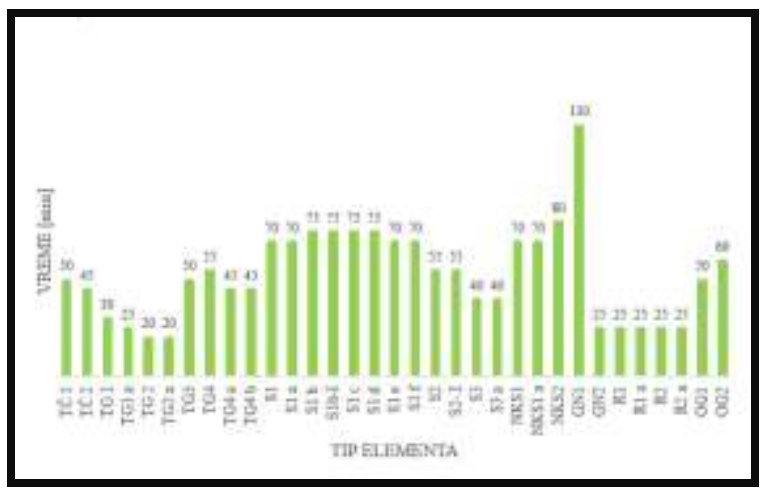

Slika 3. Ukupan utrošak oplate po tipu elementa

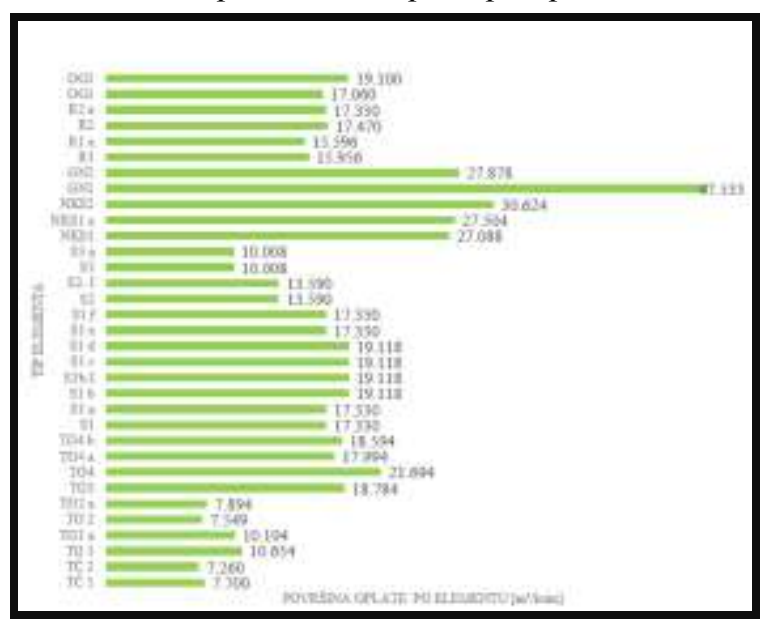

Slika 4. Prosečno vreme postavljanja oplate po tipovima elementa

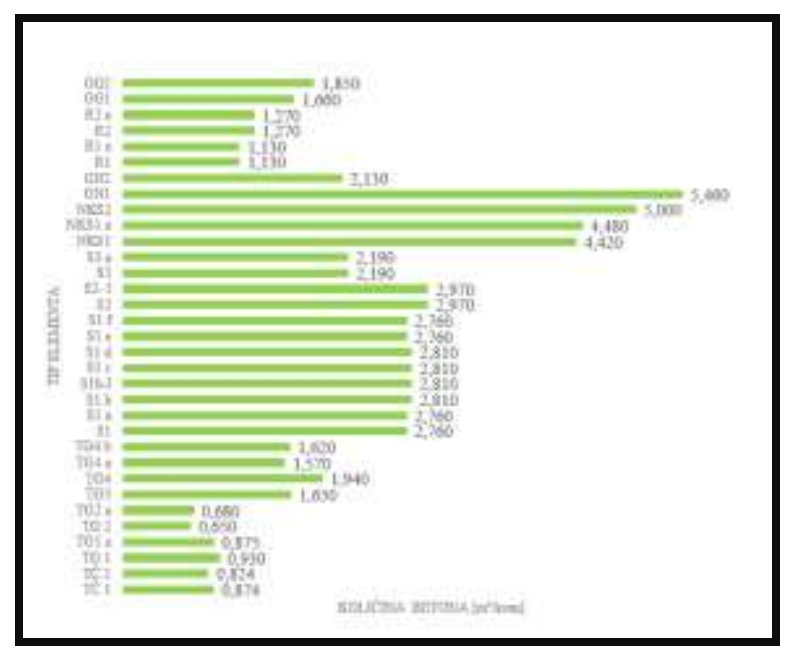

Slika 5. Ukupan utrošak betona po elementu

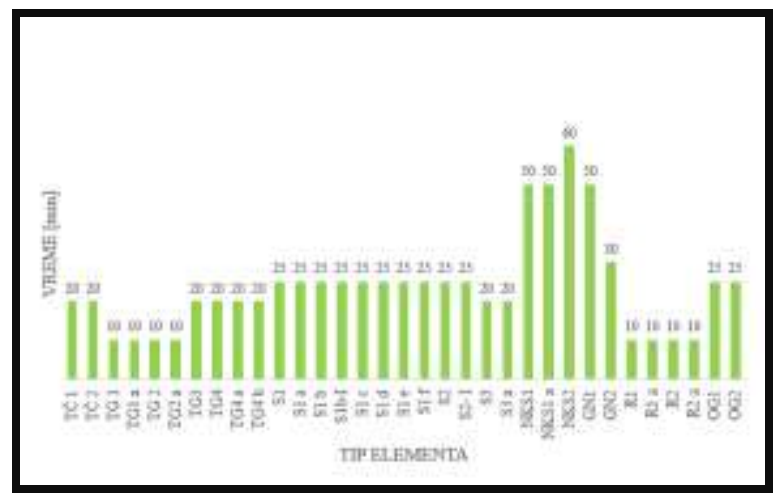

Slika 6. Prosečno vreme za ugrađivanje betona po tipovima elementa

\section{PLANIRANJE PROIZVODNJE}

Proizvodnja prefabrikovanih elemenata organizovana je $u$ proizvodnim pogonima, sa mogućim ograničenjima u prostornim kapacitetima, mehanizaciji i opremi. Sa druge strane, kontinuitet procesa izgradnje montažne hale (prefabrikacija-transport-montaža), i poštovanje ugovorenih rokova (zahtevi investitora), može ograničiti vreme proizvodnje. Vremensko i prostorno ograničenje pri planiranju proizvodnje zahteva paralelizaciju radova, a sigurno direktno utiču na dinamiku i osnovne resurse proizvodnje. Da bi se predložilo najpovoljnijije rešenje, planirana je proizvodnja elemenata konstrukcije montažne betonske hale $\mathrm{u}$ tri varijante.

- Varijanta I - bez vremenskih i prostornih ograničenja,

- Varijanta II - sa vremenskim ograničenjem i

- Varijanta III - sa ograničenim brojem kalupa.

Poštujući redosled i trajanje operacija pri proizvodnji elemenata (priprema kalupa, armiranje, betoniranje, odležavanje i zaparivanje), formirane su radne brigade (tip brigade, broj radnika), planirano je trajanje proizvodnje pojedinačno po elementu, za sve elemente jedne vrste i sračunato je ukupno vreme potrebno za proizvodnju svih elemenata konstrukcije [3]. U prvoj varijanti proizvodnja je organizovana sa jednom kompleksnom radnom brigadom, dok je kontinuitet procesa proizvodnje i uvedena ograničenja u drugoj i trećoj varijanti, rezultirao paralelizacijom radova (rad organizovan sa dve kompleksne radne brigade). 
Rezultati uporedne analize resursa, po varijantama, dati su u tabelama 8 i 9 i grafikonom na slikama 7 i 8 .

Tabela 8. Ukupna količina osnovnog materijala za sve tri varijante

\begin{tabular}{|c|c|c|c|}
\hline & $\begin{array}{c}\text { armatura } \\
{[\mathrm{kg}]}\end{array}$ & $\begin{array}{c}\text { oplata } \\
{\left[\mathrm{m}^{2}\right]}\end{array}$ & $\begin{array}{c}\text { beton } \\
{\left[\mathrm{m}^{3}\right]}\end{array}$ \\
\hline Var. I & $67.747,51$ & $1.573,28$ & 457,951 \\
\hline Var. II & $67.747,51$ & $1.573,28$ & 457,951 \\
\hline Var. III & $67.747,51$ & 868,29 & 457,951 \\
\hline
\end{tabular}

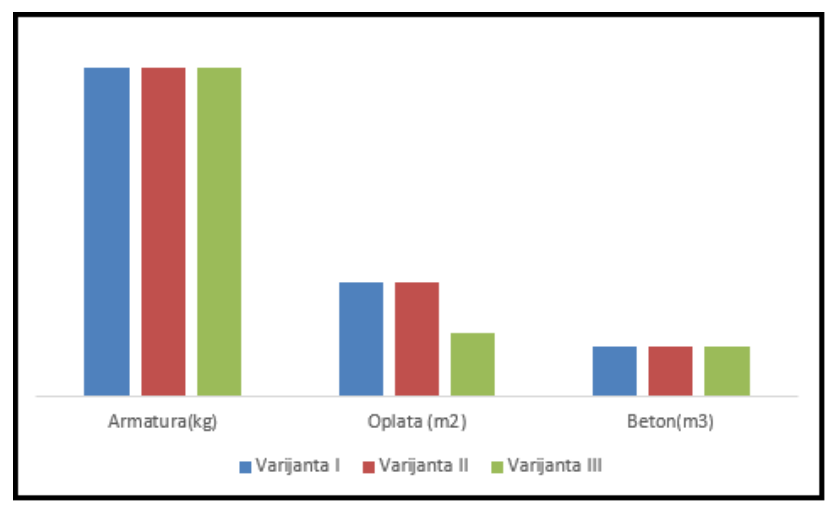

Slika 7. Uporedna analiza materijala za sve tri varijante

Tabela 9. Vreme proizvodnje i radne brigade po varijantama

\begin{tabular}{|l|c|c|c|}
\hline & vreme & brigada & radnici \\
\hline Var. I & 67 & 1 & $1 \mathrm{~A}+1 \mathrm{~T}+1 \mathrm{~B}+1 \mathrm{PR}$ \\
\hline Var. II & 33 & 2 & $1 \mathrm{~A}+1 \mathrm{~T}+1 \mathrm{~B}+1 \mathrm{PR}$ \\
\hline Var. III & 33 & 2 & $1 \mathrm{~A}+1 \mathrm{~T}+1 \mathrm{~B}+1 \mathrm{PR}$ \\
\hline
\end{tabular}

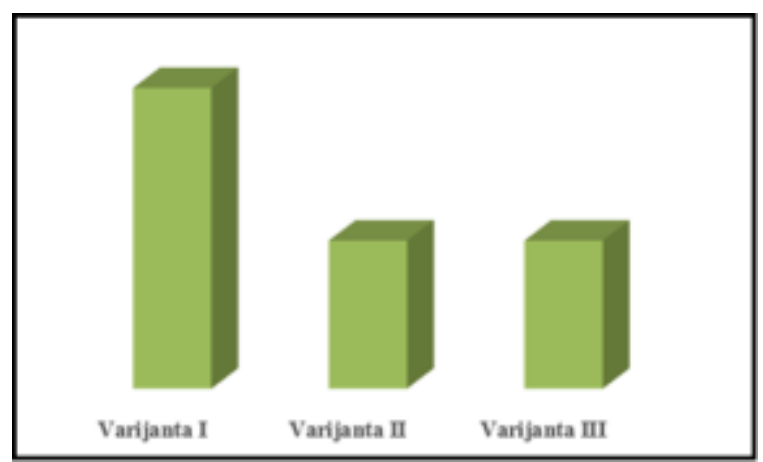

Slika 8. Uporedna analiza vremena proizvodnje za sve tri varijante

\section{ZAKLJUČAK}

$\mathrm{U}$ radu je analiziran proces proizvodnje elemenata konstrukcije montažne hale poslovnog kompleksa $u$ Rumenci. Za sve tri varijante izračunati su osnovni resursi u količinama materijala (oplata, armatura i beton) i radnoj snazi (broj i sastav radnih brigada). Proizvodnja u prvoj varijanti organizovana je sa jednom kompleksnom radnom brigadom, dok je u varijantama proizvodnje II i III primenjen princip paralelizacije, pa je proizvodnja organizovana sa dve kompleksne brigade.
Detaljni proračuni su pokazali da je za proizvodnju elemenata konstrukcije potrebno u:

- Varijanti I - 67 radna dana,

- Varijanti II - 33 radna dana, a u

- Varijanti III - 33 radna dana.

$\mathrm{Na}$ osnovu komparativne analize osnovnih resursa i vremena trajanja proizvodnje za sve tri analizirane varijante, zaključeno je da je varijanta III najpovoljnija, pa je u ovom slučaju predložena kao optimalno rešenje proizvodnje.

Detaljan pristup planiranju proizvodnje, prikazan u radu, omogućava kontrolu i praćenje svih faza prefabrikacije (kvalitet procesa i kvalitet elemenata), a izbor najpovoljnije varijante doprinosi efektima izgradnje na nivou celog objekta, vezanim za troškove i vreme izgradnje.

\section{LITERATURA}

[1] Trivunić M., Dražić J. - Montaža betonskih konstrukcija hala, AGM knjiga, Beograd, 2009.

[2] Interne građevinske norme preduzeća Novotehna, Novi Sad.

[3] Planinac J. - Analiza resursa za proizvodnju elemenata konstrukcije montažne hale u Rumenci, Diplomski (bachelor) rad, FTN Novi Sad, 2017.

\section{Kratka biografija:}

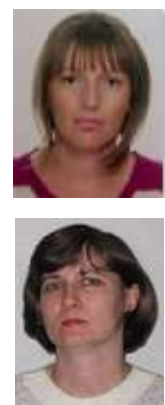

Jelena Planinac Jokić rođena je u Zenici 1988. god. Master rad na Fakultetu tehničkih nauka iz oblasti Građevinarstva - Tehnologija i organizacija građenja odbranila je 2018.god.

Jasmina Dražić rođena je u Novom Miloševu 1958.god. Doktorirala je na Fakultetu tehničkih nauka 2005.god., a od 2015.god. je u zvanju redovnog profesora. Oblast Zgradarstvo građevinske konstrukcije i tehnologije. 